\title{
Second-generation Src/Abl inhibitor bosutinib effectively induces apoptosis in human esophageal squamous cell carcinoma (ESCC) cells via inhibiting Src/ Abl signaling
}

\author{
Y. N. E. HA ${ }^{1,2}$, Y. DAI ${ }^{2}$, D. WUFUER ${ }^{2}$, M. PIDAYI², G. ANASIHAN², L. CHEN ${ }^{1,3, *}$ \\ ${ }^{1}$ Key Laboratory of Cancer Proteomics of Chinese Ministry of Health, Xiangya Hospital, Central South University, Changsha 410008, China; \\ ${ }^{2}$ Department of Respiratory, The First Affiliated Hospital of Xinjiang Medical University, Urumqi 830000, China; ${ }^{3}$ Department of Chemistry and \\ Biological Sciences, University of Southern California, Los Angeles CA 90089, USA
}

*Correspondence: 15894638656@163.com

Received January 31, 2019 / Accepted June 6, 2019

\begin{abstract}
Esophageal cancer is a prevalent type of cancer worldwide and is ranked sixth among cancer-associated mortalities. Aberrant activation of the non-receptor tyrosine kinase Src and c-Abl contribute to the progression of ESCC. Thus, targeting these kinases to treat ESCC is a promising strategy. In this paper, we report that the potent dual Src/Abl inhibitor bosutinib exerts anti-tumor effects on ESCC. Bosutinib inhibits ESCC cell proliferation in a dose-dependent manner. Furthermore, bosutinib suppresses the colony formation ability of ESCC cells. Mechanistically, bosutinib effectively inhibits c-Abl and Src and its downstream signaling pathways, PI3K/AKT/mTOR and JAK/STAT3. In addition, bosutinib enhances the cytotoxic effects of doxorubicin on ESCC cells. In summary, our results reveal that Src and Abl are potential therapeutic targets in ESCC and that the novel Src/Abl inhibitor bosutinib alone or in combination with other chemotherapeutic agents may be a viable option for treating ESCC patients.
\end{abstract}

Key words: esophageal cancer, Src/Abl inhibitor, bosutinib, doxorubicin, chemotherapeutic agents

Esophageal cancer (EC) is sixth leading common cause of cancer death and eighth most common cancer worldwide. Nearly four out of five cases occur in non-industrialized nations, with the highest rates in Asia and Africa. There are two main subtypes of esophageal cancer, squamous cell carcinoma (ESCC) and adenocarcinoma (EAC). ESCC is the predominant histological type of esophageal cancer in China, which accounts for more than $90 \%$ of esophageal cancer cases. Less common types include esophageal adenocarcinoma, melanoma and small-cell carcinoma [1-3]. Despite the improvements in patient outcomes made over the past decades, the overall survival rate for patients with esophageal cancer remains unacceptably low, and the 5 -year survival rate for these patients is still inadequate at about $15-25 \%$. Thus, there is a great need to discover additional therapeutic strategies with minimal toxicity to help patients with high-risk ESCC, including novel targeted agents.

Src, one of the members of the non-receptor tyrosine kinase family, is reported as a pivotal intermediate for regulating intracellular signaling pathways and has been frequently associated with cell migration, proliferation and apoptosis [4,5]. Aberrant activation of Src is frequently seen in the malignancy of a variety of human cancers. Src serves as the upstream signaling component of several important pathways, including PI3K/AKT/mTOR, MAPK/ERK and JAK/STAT3 signaling [6-8]. In prior studies, inhibition of Src kinase activity led to a significant decrease in cell proliferation and apoptosis induction in many cancer cells, neuroblastoma cells (NB) [9, 10], triple-negative breast cancer cells (TNBC) [11] and pancreatic ductal adenocarcinoma (PDAC) [12]. Inhibition of Src-mediated downstream signaling has been reported to exhibit anti-cancer efficacy $[13,14]$. Src-targeted chemotherapies has been shown to downregulate PI3K/Akt and JAK/STAT3 signaling, leading to cell apoptosis and inhibition of tumor growth in vivo.

The non-receptor tyrosine kinase $\mathrm{c}-\mathrm{Abl}$ is a protooncogene with multiple functions and it is associated with cell migration, proliferation, oxidative stress and DNA damage [15-17]. The role of Bcr-Abl is well-established in chronic myeloid leukemia (CML), however its role in solid tumors still remains unclear. It has been reported that 
abnormally activated c-Abl is associated with the invasion of breast cancer [18]. In human breast cancer cells and mouse fibroblasts, c-Abl is essential for Src-induced transformation of those cells by facilitating the Src/Abl/Rac/ JNK/STAT3 signaling cascade, which has been considered to be important in cell transformation [19]. In addition, inhibition the activity of c-Abl sensitizes tumor cells to apoptosis [20]. Particularly, inhibition of Src/Abl by dasatinib suppresses ESCC cell proliferation due to the upregulation of MAD2 [21], suggesting that Src and c-Abl may play a role in the proliferation of ESCC cells.

Bosutinib (SKI-606), an orally bioavailable compound, is a second-generation tyrosine kinase inhibitor, which selectively inhibits the kinase activity of Src/Abl $[22,23]$. Bosutinib, the dual inhibitor of Src and Abl, was approved by the US Food and Drug Administration (FDA) for treatment of CML [24]. However, the potential anti-tumor efficacy of the bosutinib in ESCC has not been tested.

In our study, we investigated the antitumor activity of bosutinib in ESCC cell lines. We found that bosutinib inhibited cell proliferation, induced tumor cell apoptosis in vitro and blocked the activation of Src, c-Abl as well as PI3K/ AKT/mTOR, JAK/STAT3 signaling pathways in ESCC cell lines tested. Moreover, bosutinib sensitized ECSS cells to the treatment of traditional chemotherapeutic drug like doxorubicin (Dox). Taken together, our results suggest that $\mathrm{Src}$ and $\mathrm{Abl}$ are potential therapeutic targets in ESCC, and that novel small molecule inhibitors like bosutinib, alone or in combination with chemotherapeutic agents, should be developed for patients with ESCC.

\section{Materials and methods}

Cell lines. ECA109 and KYSE450 cell lines (purchased from the Cell Bank of the Chinese Academy of Sciences, Shanghai, China) were cultured in RPMI-1640 medium (Gibco; Thermo Fisher Scientific, Inc., Waltham, MA, USA) supplemented with $10 \%$ heat-inactivated fetal bovine serum (FBS; Zhejiang Tianhang Biological Technology Co., Zhejiang, China), penicillin $(100 \mathrm{U} / \mathrm{ml})$ and streptomycin $(100 \mathrm{mg} / \mathrm{ml})$ (Gibco; Thermo Fisher Scientific, Inc.). All cells were maintained in humidified incubator at a constant temperature of $37^{\circ} \mathrm{C}$ and $5 \% \mathrm{CO}_{2}$.

Antibodies and reagents. Bosutinib was purchased from LC Laboratory (B-1788, Woburn, MA, USA). Doxorubicin (dox, D1515) and anti- $\beta$-Actin antibody (A2228) were purchased from Sigma (Sigma-Aldrich, St. Louis, USA). ZVAD-FMK was from Adooq Bioscience (CA, USA). The antibodies against p-Src (Y416, 6943S), Src (2108S), p-c-Abl (Y245, 2868S), c-Abl (sc-56887), p-STAT3 (Y705, 4904S), STAT3 (4904S), p-S6 (Ser235/236) ribosomal protein $(4858 \mathrm{~S})$, S6 ribosomal protein $(2217 \mathrm{~S})$, Caspase 3 (9662S), PARP (9532S), and anti-mouse (7076S) or antirabbit (7074S) IgG were purchased from Cell Signaling Technology (Danvers, MA, USA).
Cell viability assay. Cell viability experiments were performed with the Cell Counting Kit-8 (CCK-8, Dojindo Laboratories, Rockville, MA, USA) according to the manufacturer's instructions. Briefly, cells were seeded in 96-well plates at the density of $1 \times 10^{4}$ cells per well. After $24 \mathrm{~h}$ of culture at $37^{\circ} \mathrm{C}$, cells were either treated with increasing concentration of bosutinib and Dox, or a combination of bosutinib with Dox for 24 or $48 \mathrm{~h}$, depending on the experiments. Then a mixture of $10 \mu \mathrm{l}$ of CCK- 8 and $190 \mu \mathrm{l}$ of RPMI with $10 \%$ FBS was added to each well and incubated for one hour. The absorbance at $450 \mathrm{~nm}$ of each well was measured by the Synergy ${ }^{\mathrm{rm}} 4$ Hybrid Microplate Reader (Biotek). The $\mathrm{IC}_{50}$ value based on the cell viability data was calculated with Prism 5 (Graphpad Software Inc., La Jolla, CA). Annexin V and PI staining kit (Beyotime Biotechnologies, Jiangsu, China) was applied to quantify the cell death. After treatment, cells were washed with PBS, resuspended in $200 \mu$ l binding buffer, incubated with $5 \mu \mathrm{l}$ Annexin V-FITC and $10 \mu \mathrm{l}$ PI for $20 \mathrm{~min}$ at room temperature in the dark. The stained cells were quantified by flow cytometer (BD Bioscience, USA).

Colony formation assay. Cells were seeded in 12-well plates at $2 \times 10^{3}$ cells per well. After 24 or $48 \mathrm{~h}$, cells were incubated with bosutinib at $3 \mu \mathrm{M}$, or $5 \mu \mathrm{M}$ for $72 \mathrm{~h}$ and then cultured in drug-free medium for about 2 weeks. After that, cells were fixed and stained with methanol/crystal violet for $10 \mathrm{~min}$ and photographed. Each experiment was performed in triplicate.

Anchorage-independent growth assay. Cell anchorageindependent growth abilities were evaluated by soft agar assays as described $[25,26]$. Briefly, in six-well plates, the bottom layer was made by mixing $2 \mathrm{ml}$ of $0.5 \%$ agar and media solution and added to each well until semi-solid. The $1.5 \mathrm{ml}$ top agar layer was made of $0.3 \%$ agar and media solution, and each ESCC cell line was counted and added to the mixture at the density of $1 \times 10^{4}$ cells/well along with the indicated concentrations of bosutinib. Cells were grown at $37^{\circ} \mathrm{C}$ for $2-3$ weeks and subsequently stained with $500 \mu$ l of $5 \mathrm{mg} / \mathrm{ml}$ Thiazolyl Blue Tetrazolium Bromide (MTT, M5655, Sigma). After $4 \mathrm{~h}$, images were captured by the microscope and colonies were counted. Each assay was performed in triplicates.

Western blot analysis. For protein immunoblotting, after the indicated treatments, cells were washed twice with cold PBS and then lysed in RIPA buffer $(150 \mathrm{mM} \mathrm{NaCl}$, $50 \mathrm{mM}$ Tris- $\mathrm{HCl}$ at $\mathrm{pH} 7.4,50 \mathrm{mM}$ sodium fluoride, $1 \mathrm{mM}$ EDTA, $1 \mathrm{mM}$ dithiothreitol, $1 \mathrm{mM}$ phenylmethylsulfonyl fluoride, $1 \mathrm{mM}$ benzamidine, $0.1 \mathrm{mM}$ sodium orthovanadate, $10 \mu \mathrm{g} / \mathrm{mL}$ leupeptin, $1 \% \mathrm{NP}-40,0.25 \%$ sodium deoxycholate, and supplemented with phosphatase inhibitor cocktail 2 and 3 (p5726 and p0044, Sigma). Protein concentration was determined by Bio-Rad Bradford protein assay and equal amounts of protein were loaded for immunoblot analysis. Lysates $(50 \mu \mathrm{g}$ protein) were separated by the SDS-PAGE, and then transferred to PVDF (polyvinylidence fluoride) membranes (BioRad). Membranes were blocked in 
$5 \%$ milk for $1 \mathrm{~h}$ at room temperature, and then incubated with the indicated primary antibodies overnight at $4^{\circ} \mathrm{C}$. The membranes were then incubated with anti-mouse or anti-rabbit IgG conjugated with horseradish peroxidase at room temperature for $1 \mathrm{~h}$. Chemiluminescent visualization was detected by the ECL-Plus Western detection system (GE Health Care, Buckinghamshire, UK). Membranes were re-probed with $\beta$-actin antibody as a loading control for all experiments.

Statistical analysis. Statistical analysis was performed using GraphPad Prism 5 software. All values are presented as mean \pm standard deviation. $p$-values $<0.05$ were considered statistically significant. Student's t-test (two-tailed) and one way ANNOVA and analysis of variance (Dunnett's multiple comparison post-test) were used to analyze differences between the drug treatment groups and control group.

\section{Results}

Bosutinib suppresses the proliferation of ESCC cells. To assess the antitumor effect of bosutinib on ESCC, we used two ESCC lines ECA109 and KYSE450, which were treated with bosutinib at the indicated concentrations of $0.05 \mu \mathrm{M}$ to $10 \mu \mathrm{M}$ for $48 \mathrm{~h}$, then subjected to CCK- 8 assay. The results demonstrated that cell viability was greatly reduced by bosutinib in tested ESCC cell lines in a dose-dependent manner (Figure 1A). Both ECA109 and KYSE450 cells were relatively sensitive to the treatment of bosutinib with $\mathrm{IC}_{50}$ ranged from $2.717 \mu \mathrm{M}$ to $3.122 \mu \mathrm{M}$ (Figure $1 \mathrm{~B}$ ). These results indicate that bosutinib significantly inhibits ESCC cell growth in a dose-dependent manner.

A
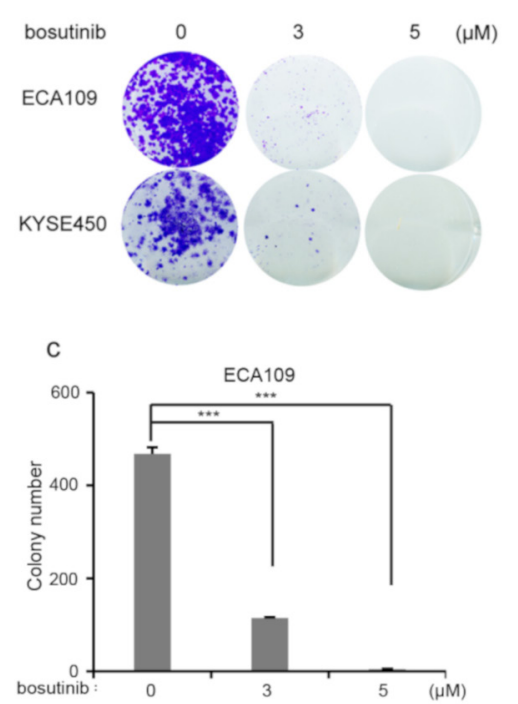

Bosutinib inhibits colony formation of abilities of ESCC cells. To further validate the inhibitory effect of bosutinib on cell growth, we performed a cellular colony formation assay. Cells were treated with bosutinib at concentrations of $0 \mu \mathrm{M}, 3 \mu \mathrm{M}$, and $5 \mu \mathrm{M}$ for $72 \mathrm{~h}$ and then cultured in drug-free medium for about 2 weeks. Treatment with bosutinib remarkably inhibited tumor cell growth compared with control in both cell lines tested (Figure 2A). The capability to form colonies in an anchorage-independent manner in soft agar is also one of the most distinctive characteristics of cancer

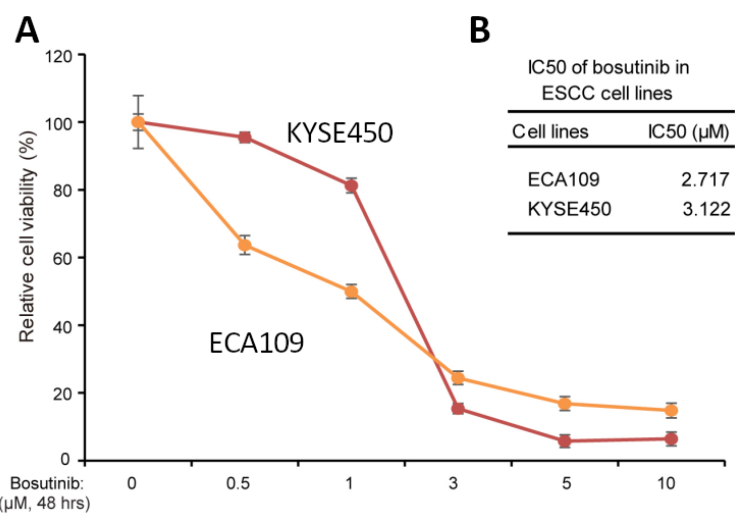

Figure 1. Bosutinib suppresses the proliferation of ESCC cells. A) Two ESCC cell lines, ECA109 and KYSE450, were treated with increasing concentration of bosutinib for $48 \mathrm{~h}$. Cell viability was measured by performing the Cell Counting Kit-8 (CCK-8) assay. p-values $<0.05\left({ }^{*}\right)$, or $\mathbf{p}<0.001$ $\left.{ }^{* * *}\right)$ (Student's t-test, two-tailed) were indicated. $\mathrm{B}$ ) The $\mathrm{IC}_{50}$ values of bosutinib on each ESCC cell lines were calculated by using Graphpad prism 5.0.

B
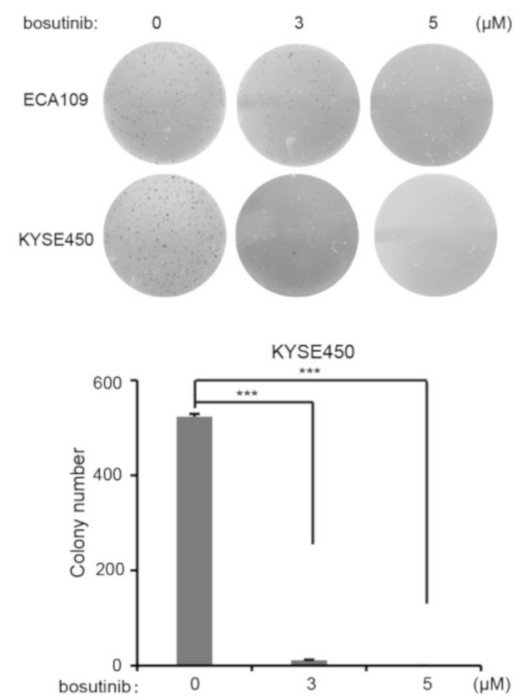

Figure 2. Src inhibitor bosutinib inhibits colony formation of abilities of ESCC cells. A) Two ESCC cell lines were seeded in 12 -well plates at $2 \times 10^{3}$ per well, then incubated with bosutinib at $0 \mu \mathrm{M}, 3 \mu \mathrm{M}$, or $5 \mu \mathrm{M}$ for $48 \mathrm{~h}$ and cultured in drug free medium for about 2 weeks. Cell colonies were fixed, stained with crystal violet and photographed. B) ECA109 and KYSE450 cells were seeded in 6-well plates in soft agar with increasing concentrations of bosutinib and allowed to grow for 2-3 weeks. Then, crystal violet staining was performed and the images were captured. C) Colony numbers from (B) were presented as mean \pm S.D. p-values $\left.<0.001{ }^{* * *}\right)$ (Student's t-test, two-tailed) were indicated. 
cells. To assess whether bosutinib impair the anchorageindependent growth ability of ESCC cells, we performed soft agar assays also. ECA109 and KYSE450 cells were cultured with bosutinib at $0 \mu \mathrm{M}, 3 \mu \mathrm{M}$ or $5 \mu \mathrm{M}$ for three weeks and then visible colonies were fixed and stained. Compared with untreated control groups, the number of colonies were significantly reduced in all bosutinib-treated groups, indicating that bosutinib inhibited colony formation in ESCC cell lines tested (Figures 2B and 2C).

Bosutinib inhibits Src and c-Abl activity, as well as the activation of PI3K/Akt/mTOR and JAK/STAT3 signaling and induces apoptosis in ESCC cells. We aimed to determine the molecular mechanisms, which were responsible for the cytotoxicity of bosutinib in ESCC cells. Both ECA109 and KYSE cells were treated with bosutinib for different time points $(0-12 \mathrm{~h})$ and we measured the phosphorylation levels of Src and its downstream effectors. As shown in Figure 3, bosutinib significantly inhibited the phosphorylation level of p-Src (Y416), p-c-Abl (Y245) and p-STAT3 (Y705) in the cells tested. The ribosomal protein S6 kinase acts downstream of the mammalian target of rapamycin (mTOR) and bosutinib also effectively suppressed the activation of p-S6 (S235/236), in the tested cell lines (Figures $3 \mathrm{~A}$ and $3 \mathrm{~B}$ ). Furthermore, bosutinib alone induced cell death via increasing PARP cleavage in a dose dependent manner (Figure 3C). Collectively, these data demonstrate that bosutinib induced cell

A
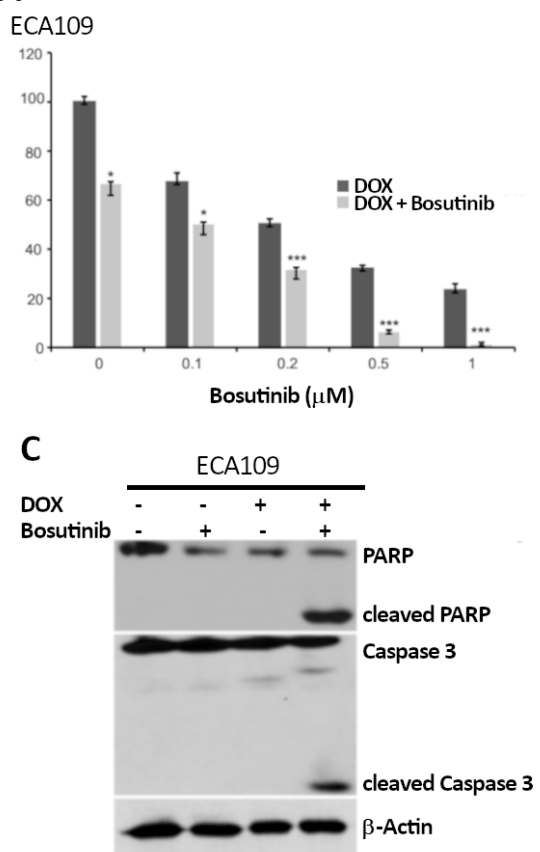

A

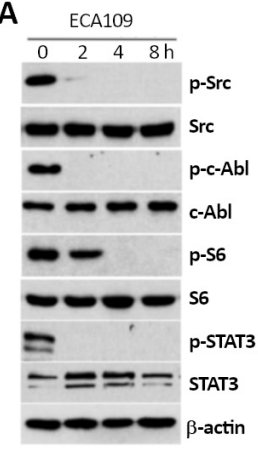

C

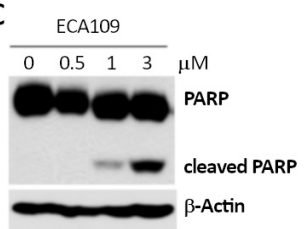

B
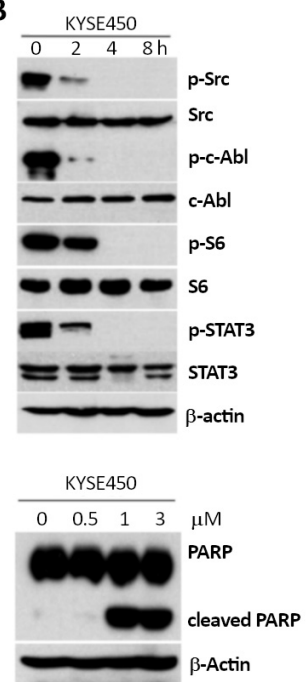

Figure 3. Bosutinib inhibits Src and c-Abl activity, as well as the activation of PI3K/Akt/mTOR and JAK/STAT3 signaling and induces apoptosis in ESCC cells. A and B) ECA109 and KYSE450 cells were treated with $5 \mu \mathrm{M}$ of bosutinib for $0,2,4$ and $8 \mathrm{~h}$ and the cells were lysed and subjected to immunoblotting with the indicated antibodies. $\beta$-actin was used as a loading control in all experiments. C) ECA109 and KYSE450 cells were treated with increasing concentrations of bosutinib $(0,0.5,1$ and $3 \mu \mathrm{M})$ for $12 \mathrm{~h}$ and the cells were lysed and subjected to immunoblotting with indicated antibodies. $\beta$-Actin was used as a loading control in all experiments.

B
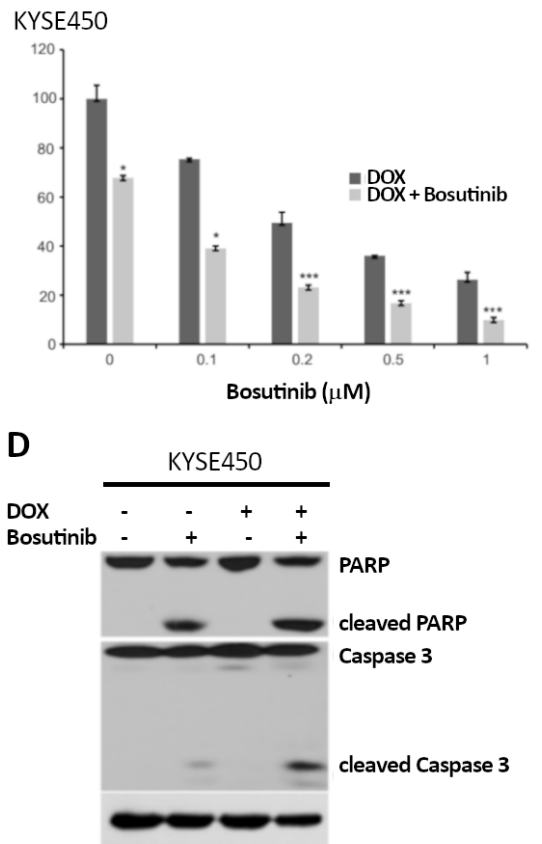

Figure 4. Bosutinib significantly enhances the cytotoxic effect of Doxorubicin on ESCC cell lines. A and B) ECA109 and KYSE450 cells were seeded in 96-well plates and were incubated with the indicated concentrations of Dox plus DMSO or bosutinib $(0.5 \mu \mathrm{M})$ for $24 \mathrm{~h}$. Cell viability was assessed by the CCK-8 assay. Results are represented as $\%$ vehicle \pm SD. p-values $<0.05\left(^{*}\right), p<0.01\left({ }^{* *}\right)$, or $\mathbf{p}<0.001\left(^{* * *}\right.$ (Student's t-test, two-tailed) were indicated. C and D) ECA109 and KYSE450 cells were treated with either Dox $(1 \mu \mathrm{M})$, or bosutinib $(0.5 \mu \mathrm{M})$ alone or in combinations for $12 \mathrm{~h}$. All samples were then collected, subjected to SDS-PAGE, and immunoblotted with PARP and Caspase 3 antibodies. $\beta$-Actin was used as a loading control for whole cell extracts in all experiments. 
apoptosis by blocking the activation of Src, c-Abl, PI3/AKT/ mTOR and JAK/STAT3 pathways in ESCC cells.

Bosutinib significantly enhances the cytotoxic effect of Doxorubicin on ESCC cell lines. Since ESCC cell proliferation was effectively inhibited by the treatment of bosutinib, we reasoned that bosutinib may sensitize ESCC cells to the treatment of conventional drug Dox. To test our hypothesis, we treated the cells with either Dox alone or combined with bosutinib at indicated concentrations for $48 \mathrm{~h}$. We found that the cytotoxic effects of Dox on both ESCC cells were significantly enhanced when treated in combination with low doses of bosutinib (Figures 4A and 4B). Consistently, immunoblotting analyses showed that bosutinib boosted Dox-induced cell death by increasing Caspase- 3 and PARP cleavages in the combination treatment groups compared to the bosutinib or Dox alone treatment groups (Figures 4C and 4D). Moreover, Annexin $\mathrm{V}$ and PI staining showed that bosutinib combined with Dox increased cell death (Figure 5A). Furthermore, to determine whether the apoptosis induced by bosutinib was caspase-dependent, the caspase inhibitor ZVAD-FMK was co-administered and bosutinib-induced cell death was significantly inhibited (Figure 5B).

\section{Discussion}

The non-receptor tyrosine kinase Src has been involved in multiple cancer-related process including proliferation and survival through Src-mediated PI3K/AKT/mTOR, MAPK/ ERK and JAK/STAT3 signaling [27-29], therefore it has been recently indicated as a promising therapeutic target in the treatment of solid tumors including ESCC [30]. In addition, it has been reported that Src is not only involved in tumor progression but also associated with the resistance to anticancer drugs in traditional and targeted therapies [31]. Other studies have shown the influence of inhibition of Src activity by dasatinib on cisplatin sensitivity in ESCC cells [32]. Our results indicate that the novel dual Src/Abl inhibitor bosutinib, inhibited the proliferation of ESCC cells in a time-dependent manner, attenuated colony forming ability and increased apoptosis in tested ESCC cells. Also, we found that bosutinib suppressed the activities of Src and Src-mediated PI3K/AKT/mTOR and JAK/STAT3 signaling pathways in ESCC cells.

Chemoresistance has frequently been seen as one of the main clinical obstacles, which cause the relapse in patients, especially in high-risk ESCC patients. Thus, clarifying the molecular mechanisms that are responsible for chemoresistance is of vital importance. In the present study, we demonstrated that although bosutinib alone exerted cytotoxicity in ESCC cells by suppressing the activation of its targeted Src and c-Abl, cells showed further sensitivity to the treatment with combination of bosutinib and Dox. It is notable that bosutinib may sensitize ESCC to Dox chemotherapy and thus lessen Dox resistance and toxicity. Consistent with these

A

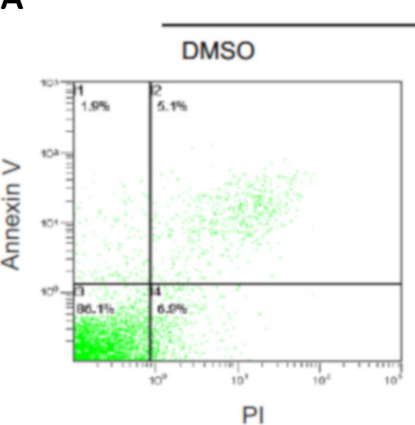

B

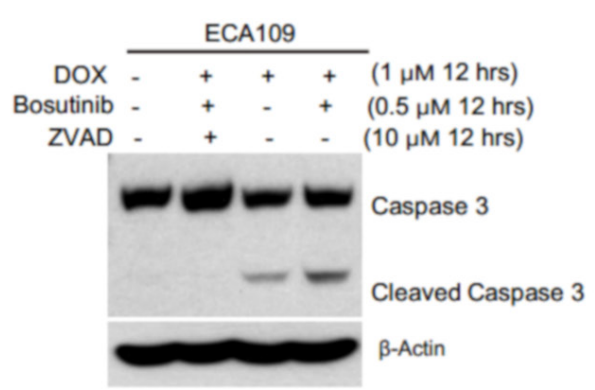

ECA109

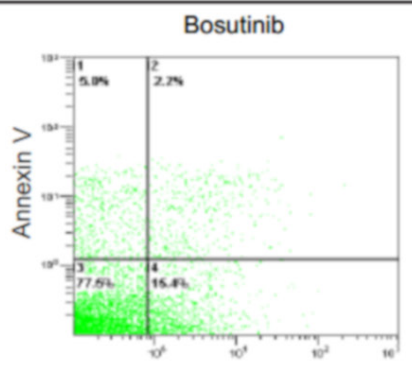

$\mathrm{PI}$

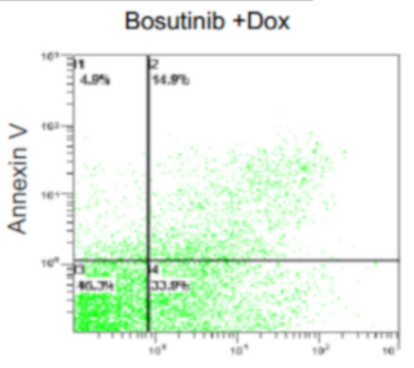

$\mathrm{PI}$

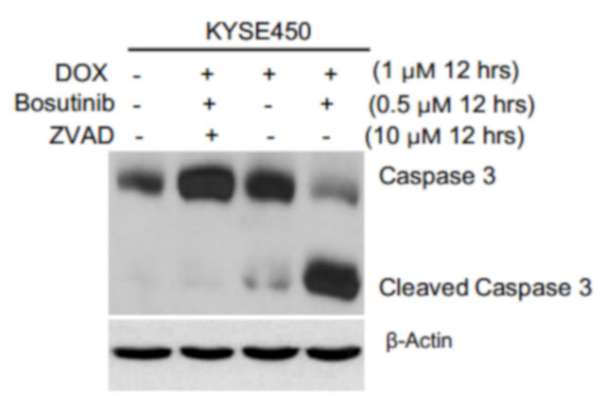

Figure 5. Bosutinib significantly enhances the cytotoxic effect of Doxorubicin on ESCC cell lines. A) Cell apoptosis of ECA109 was detected by flow cytometry $12 \mathrm{~h}$ after bosutinib $(0.5 \mu \mathrm{M})$ treatment with or without Dox $(1 \mu \mathrm{M})$. B) ECA109 and KYSE450 cells were treated with indicated concentrations of bosutinib for 0-12 h with or without Dox or ZVAD and the cells were lysed and subjected to immunoblotting with the indicated antibodies. $\beta$-Actin was used as a loading control in all experiments. 
findings, it has been reported that some bosutinib exacerbates Dox-induced cytotoxicity in neuroblastoma (NB) and sensitizes NB cells to Dox [9]. Collectively, these findings suggest that bosutinib could be beneficial as an addition to conventional drug Dox and it might be an effective strategy for treating ESCC patients, enabling the use of lower doses of Dox and reducing side effects.

Multiple Src/Abl inhibitors have been studied in the laboratory and clinic. Imatinib, the first generation Bcr-Abl inhibitor, has shown activity in patients with CML and gastrointestinal stromal tumors and was approved for the treatment of these patients $[33,34]$. However, there is a demand to treat patients with imatinib-resistant Bcr-Abl mutants, which gave rise to the development inhibitors like dasatinib, nilotinib and bosutinib that are the secondgeneration tyrosine kinase inhibitors. As a second generation $\mathrm{Src} / \mathrm{Abl}$ inhibitor, bosutinib has a much broader therapeutic index than imatinib and bosutinib targets the active kinase domain of c-Abl and inhibits both c-Abl and Bcr-Abl fusion protein at a lower $\mathrm{IC}_{50}$ than imatinib [35]. Another advantage of bosutinib is that it might be safe and effective first-line treatment for patients with chronic phase CML [36]. Despite the fact that bosutinib as a single agent has been approved by United States Food and Drug Administration (FDA) for treating patients with CML [24], its efficacy in ESCC and other diseases including survival rate, relapse rate of the patients after bosutinib treatment remains to be determined.

In summary, by studying two ESCC cell lines, we provide compelling evidence that bosutinib alone could suppress proliferation and induce apoptosis in ESCC cells by blocking $\mathrm{Src}, \mathrm{c}-\mathrm{Abl}$ and downstream signaling pathways. Promising combinatorial effects are also seen with traditional chemotherapeutic agents. Our data suggest that $\mathrm{Src}$ and $\mathrm{c}-\mathrm{Abl}$ are promising therapeutic targets in ESCC, and our study offers the possibility for rational use of $\mathrm{Src} / \mathrm{Abl}$ inhibitors like bosutinib as a new approach for the treatment of ESCC patients.

Acknowledgements: This work was supported by the Natural Science Foundation of Xinjiang, China (No.2017D01C328). We would like to thank Fazal for scientific editing of the manuscript.

\section{References}

[1] JEMAL A, CENTER MM, DESANTIS C, WARD EM. Global patterns of cancer incidence and mortality rates and trends. Cancer Epidemiol Biomarkers Prev 2010; 19: 189318907. https://doi.org/10.1158/1055-9965.EPI-10-0437

[2] POHL H, WELCH HG. The role of overdiagnosis and reclassification in the marked increase of esophageal adenocarcinoma incidence. J Natl Cancer Inst 2005; 97: 142-146. https://doi.org/10.1093/jnci/dji024

[3] ENZINGER PC, MAYER RJ. Esophageal cancer. N Engl J Med 2003; 349: 2241-2252. https://doi.org/10.1056/NEJMra035010
[4] CHATZIZACHARIAS NA, KOURAKLIS GP, GIAGINIS CT, THEOCHARIS SE. Clinical significance of Src expression and activity in human neoplasia. Histol Histopathol 2012; 27: 677-692. https://doi.org/10.14670/HH-27.677

[5] RUSSELLO SV, SHORE SK. SRC in human carcinogenesis. Front Biosci 2004; 9: 139-144.

[6] PARK J, KIM S, JOH J, REMICK SC, MILLER DM et al. MLLT11/AF1q boosts oncogenic STAT3 activity through Src-PDGFR tyrosine kinase signaling. Oncotarget 2016; 7: 43960-43973. https://doi.org/10.18632/oncotarget.9759

[7] SUMMY JM, GALLICK GE. Src family kinases in tumor progression and metastasis. Cancer Metastasis Rev 2003; 22: 337-358.

[8] YANG WR, ZHU FW, ZHANG JJ, WANG Y, ZHANG $\mathrm{JH}$ et al. PI3K/Akt Activated by GPR30 and Src Regulates 17beta-Estradiol-Induced Cultured Immature Boar Sertoli Cells Proliferation. Reprod Sci 2017; 24: 57-66. https://doi. org/10.1177/1933719116649696

[9] BIEERKEHAZHI S, CHEN Z, ZHAO Y, YU Y, ZHANG $\mathrm{H}$ et al. Novel Src/Abl tyrosine kinase inhibitor bosutinib suppresses neuroblastoma growth via inhibiting Src/ Abl signaling. Oncotarget 2017; 8: 1469-1480. https://doi. org/10.18632/oncotarget.13643

[10] VITALI R, MANCINI C, CESI V, TANNO B, PISCITELLI $\mathrm{M}$ et al. Activity of tyrosine kinase inhibitor Dasatinib in neuroblastoma cells in vitro and in orthotopic mouse model. Int J Cancer 2009; 125: 2547-2555. https://doi.org/10.1002/ ijc. 24606

[11] ADAMS BD, WALI VB, CHENG CJ, INUKAI S, BOOTH CJ et al. miR-34a Silences c-SRC to Attenuate Tumor Growth in Triple-Negative Breast Cancer. Cancer Res 2016; 76: 927939. https://doi.org/10.1158/0008-5472.CAN-15-2321

[12] SONG X, CHEN H, ZHANG C, YU Y, CHEN Z et al. SRC3 inhibition blocks tumor growth of pancreatic ductal adenocarcinoma. Cancer Lett 2019; 442: 310-319. https://doi. org/10.1016/j.canlet.2018.11.012

[13] CHEN J, ELFIKY A, HAN M, CHEN C, SAIF MW. The role of Src in colon cancer and its therapeutic implications. Clin Colorectal Cancer 2014; 13: 5-13. https://doi.org/10.1016/j. clcc.2013.10.003

[14] ABDSALEH S, WARNBERG F, AZAVEDO E, LINDGREN PG, AMINI RM. Comparison of core needle biopsy and surgical specimens in malignant breast lesions regarding histological features and hormone receptor expression. Histopathology 2008; 52: 773-775. https://doi.org/10.1111/j.13652559.2008.03014.x

[15] SHAUL Y, BEN-YEHOYADA M. Role of c-Abl in the DNA damage stress response. Cell Res 2005; 15: 33-35. https://doi. org/10.1038/sj.cr.7290261

[16] PLATTNER R, PENDERGAST AM. Activation and signaling of the Abl tyrosine kinase: bidirectional link with phosphoinositide signaling. Cell Cycle 2003; 2: 273-274.

[17] PENDERGAST AM. The Abl family kinases: mechanisms of regulation and signaling. Adv Cancer Res 2002; 85: 51-100.

[18] SRINIVASAN D, PLATTNER R. Activation of Abl tyrosine kinases promotes invasion of aggressive breast cancer cells. Cancer Res 2006; 66: 5648-5655. https://doi. org/10.1158/0008-5472.CAN-06-0734 
[19] LUPINO E, RAMONDETTI C, BUCCINNA B, PICCININI M. Exposure of neuroblastoma cell lines to imatinib results in the upregulation of the CDK inhibitor p27(KIP1) as a consequence of c-Abl inhibition. Biochem Pharmacol 92: 235-250. https://doi.org/10.1016/j.bcp.2014.09.016

[20] SRINIVASAN D, SIMS JT, PLATTNER R. Aggressive breast cancer cells are dependent on activated Abl kinases for proliferation, anchorage-independent growth and survival. Oncogene 2008; 27: 1095-1105. https://doi.org/10.1038/ sj.onc. 1210714

[21] WANG L, GUO B, WANG R, JIANG Y, QIN S et al. Inhibition of cell growth and up-regulation of MAD2 in human oesophageal squamous cell carcinoma after treatment with the Src/Abl inhibitor dasatinib. Clin Sci (Lond) 2012; 122: 13-24. https://doi.org/10.1042/CS20110230

[22] BOSCHELLI DH, YE F, WANG YD, DUTIA M, JOHNSON SL et al. Optimization of 4-phenylamino-3-quinolinecarbonitriles as potent inhibitors of Src kinase activity. J Med Chem 2001; 44: 3965-3977. https://doi.org/10.1021/ jm0102250

[23] GOLAS JM, ARNDT K, ETIENNE C, LUCAS J, NARDIN $\mathrm{D}$ et al. SKI-606, a 4-anilino-3-quinolinecarbonitrile dual inhibitor of Src and Abl kinases, is a potent antiproliferative agent against chronic myelogenous leukemia cells in culture and causes regression of K562 xenografts in nude mice. Cancer Res 2003; 63: 375-381.

[24] STANSFIELD L, HUGHES TE, WALSH-CHOCOLAAD TL. Bosutinib: a second-generation tyrosine kinase inhibitor for chronic myelogenous leukemia. Ann Pharmacother 2013; 47: 1703-1711. https://doi.org/10.1177/1060028013503124

[25] CHEN Z, WANG Z, PANG JC, YU Y, BIEERKEHAZHI S et al. Multiple CDK inhibitor dinaciclib suppresses neuroblastoma growth via inhibiting CDK2 and CDK9 activity. Sci Rep 2016; 6: 29090. https://doi.org/10.1038/srep29090

[26] SHI Y, YU Y, WANG Z, WANG H, BIEERKEHAZHI S et al. Second-generation proteasome inhibitor carfilzomib enhances doxorubicin-induced cytotoxicity and apoptosis in breast cancer cells. Oncotarget 2016; 7: 73697-73710. https://doi.org/10.18632/oncotarget.12048

[27] NAM S, WEN W, SCHROEDER A, HERRMANN A, YU H et al. Dual inhibition of Janus and Src family kinases by novel indirubin derivative blocks constitutively-activated Stat 3 signaling associated with apoptosis of human pancreatic cancer cells. Mol Oncol 2013; 7: 369-378. https://doi.org/10.1016/j. molonc.2012.10.013
[28] ZHAO GS, GAO ZR, ZHANG Q, TANG XF, LV YF et al. TSSC3 promotes autophagy via inactivating the Src-mediated $\mathrm{PI} 3 \mathrm{~K} / \mathrm{Akt} / \mathrm{mTOR}$ pathway to suppress tumorigenesis and metastasis in osteosarcoma, and predicts a favorable prognosis. J Exp Clin Cancer Res 2018; 37: 188. https://doi. org/10.1186/s13046-018-0856-6

[29] YANG P, SU C, LUO X, ZENG H, ZHAO L et al. Dietary oleic acid-induced CD36 promotes cervical cancer cell growth and metastasis via up-regulation Src/ERK pathway. Cancer Lett 2018; 438: 76-85. https://doi.org/10.1016/j.canlet.2018.09.006

[30] ZHANG S, YU D. Targeting Src family kinases in anticancer therapies: turning promise into triumph. Trends Pharmacol Sci 2012; 33: 122-128. https://doi.org/10.1016/j. tips.2011.11.002

[31] JIN Y, CAI Q, SHENOY AK, LIM S, ZHANG Y et al. Src drives the Warburg effect and therapy resistance by inactivating pyruvate dehydrogenase through tyrosine-289 phosphorylation. Oncotarget 2016; 7: 25113-25124. https://doi. org/10.18632/oncotarget.7159

[32] CHEN J, LAN T, ZHANG W, DONG L, KANG N et al. Dasatinib enhances cisplatin sensitivity in human esophageal squamous cell carcinoma (ESCC) cells via suppression of PI3K/AKT and Stat3 pathways. Arch Biochem Biophys 2015; 575: 38-45. https://doi.org/10.1016/j.abb.2014.11.008

[33] COHEN MH, WILLIAMS G, JOHNSON JR, DUAN J, GOBBURU J et al. Approval summary for imatinib mesylate capsules in the treatment of chronic myelogenous leukemia. Clin Cancer Res 2002; 8: 935-942.

[34] FDA grants imatinib (Gleevec) full approval for adjuvant treatment of GIST. Oncology (Williston Park) 2012; 26: 264, 309.

[35] HANTSCHEL O, GREBIEN F, SUPERTI-FURGA G. The growing arsenal of ATP-competitive and allosteric inhibitors of BCR-ABL. Cancer Res 2012; 72: 4890-4895. https://doi. org/10.1158/0008-5472.CAN-12-1276

[36] CORTES JE, GAMBACORTI-PASSERINI C, DEININGER MW, MAURO MJ, CHUAH C et al. Bosutinib Versus Imatinib for Newly Diagnosed Chronic Myeloid Leukemia: Results From the Randomized BFORE Trial. J Clin Oncol 2018; 36: 231-237. https://doi.org/10.1200/JCO.2017.74.7162 